Efektor, Volume 8 Issue 1, 2021, Pages 59-68

Available online at: http://ojs.unpkediri.ac.id/index.php/efektor-e

DOI: https://doi.org/10.29407/e.v8i1.15868

\title{
Ragam Kohesi Leksikal Pada Rubrik Pembaca Menulis Koran Jawa Pos
}

\author{
Andri Pitoyo \\ andripitoyo@unpkediri.ac.id \\ Pendidikan Bahasa dan Sastra Indonesia \\ FKIP Universitas Nusantara PGRI Kediri Jawa Timur Indonesia \\ JI. KH. Ahmad Dahlan No. 76 Mojoroto Kota Kediri Jawa Timur Indonesia
}

\begin{abstract}
This study emphasizes the usage description of (1) lexical cohesion in the form of repetitions in the Pembaca Menulis rubric of Jawa Pos newspapers, (2) lexical cohesion in the form of synonyms in the Pembaca Menulis rubric of Jawa Pos newspapers, and (3) lexical cohesion in the form of antonyms in the Pembaca Menulis rubric of Jawa Pos newspapers. Newspapers are source of written news that can be read at any time. In addition to presenting news that is happening around the community, newspapers are also place to express aspirations, one of which is the Pembaca Menulis rubric of Jawa Pos newspapers from May and June 2020 editions. A good and complete text requires cohesive sentences both grammatically and lexically. The data source of this research is the Jawa Pos newspapers from May and June 2020 editions which are taken randomly. This research is a qualitative research that uses a critical text analysis approach. The results of the study show that there are repetitions, synonyms, and antonyms in the May and June 2020 editions of Pembaca Menulis rubric of Jawa Pos Newspapers.
\end{abstract}

Keywords : text, lexical cohesion, repetition, synonym, antonym

\section{ABSTRAK}

Penelitian ini menekankan pada deskripsi pemakaian (1) kohesi leksikal berupa repetisi pada rubrik Pembaca Menulis Koran Jawa Pos, (2) kohesi leksikal berupa sinonim pada rubrik Pembaca Menulis koran Jawa Pos, dan (3) kohesi leksikal berupa antonim pada rubrik Pembaca Menulis koran Jawa Pos. Koran merupakan sumber berita tertulis yang dapat dibaca setiap saat. Selain menyajikan berita yang terjadi di sekitar masyarakat, koran juga menjadi tempat untuk menuangkan aspirasi, salah satunya adalah rubrik Pembaca Menulis koran Jawa Pos edisi Mei dan Juni 2020.Wacana yang baik dan utuh mensyaratkan kalimatkalimat yang kohesif baik secara gramatikal maupun leksikalnya. Sumber data penelitian ini adalah koran koran Jawa Pos bulan Mei dan Juni 2020 yang diambil secara random. Penelitian ini merupakan penelitian kualitatif yang menggunakan rancangan analisis wacana kritis. Hasil penelitian menunjukkan bahwa dalam rubrik Pembaca Menulis koran Jawa Pos edisi Mei dan Juni 2020 terdapat repetisi, sinonim, dan antonim.

Kata Kunci : wacana, kohesi leksikal, repetisi, sinonim, antonim

\section{PENDAHULUAN}

Semua macam informasi yang ada di dunia dapat diperoleh melalui media massa. Usaha pemerolehan informasi yang dimaksud merupakan wahan komunikasi penting untuk mendidik dan mengetahui berbagai pengetahuan yang berkembang. Media massa cetak praktis dan efektif yang selama ini cenderung dimanfaatkan masyarakat adalah Koran (Evi \& Bakti, 2016). Koran yang terbit setiap hari menyampaikan suatu berita dan informasi yang terjadi di sekitar bahkan di seluruh dunia dengan cepat dan sesuai fakta di lapangan. Dengan semakin berkembangnya zaman, koran tidak hanya diterbitkan dalam bentuk cetakan kertas, tetapi juga dapat diakses melalui internet. Sehingga semakin memudahkan masyarakat untuk memperoleh informasi secara cepat. 


\section{Efektor, Volume 8 Issue 1, 2021, Pages 59-68 \\ Andri Pitoyo}

Media pembelajaran yang praktis didapatkan saat ini adalah media cetak. Jawa Pos merupakan salah satu media massa cetak yang masih eksis di Indonesia. Koran ini juga bisa digunakan sebagai saranan pembelajaran. Surat Kabat tersebut merupakan surat kabar yang terbit secara nasional, khususnya di pulau Jawa yang di dalamnya memiliki beragam rubrik atau kolom, di antaranya Pembaca menulis. Kolom pembaca menulis merupakan kolom yang berisi tulisan pembaca yang memuat ide kritis dalam bentuk tanggapan mengenai sesuatu, masukan, keinginan, informasi, laporan, ucapan terimakasih dan berbagai hal yang dituangkan secara efektif. Sebagai sebuah wacana sekaligus media informasi cetak yang baik, kolom pembaca menulis tentu memprioritaskan kualitas tulisan yang akan diterbitkan. Disamping itu, rubrik pembaca menulis memiliki karakter khas dari aspek bahasa. Hal ini disebabkan karena para penulis berasal dari berbagai daerah, beragam strata sosial, budaya, dan penguasaan bahasa. Berdasarkan telaah awal ditemukan beragam gaya penulisan yang muncul, terutama penggunaan penanda kohesi di setiap kalimat yang digunakan.

Aspek penting dalam sebuah wacana di antaranya adalah kohesi. Pernyataan tersebut menekankan pada maksud bahwa pemahaman terhadap isi atau substansi tuturan seseorang ditentukan oleh adanya kohesi (Danglli \& Abazaj, 2014). Karena kohesi mampu mengaitkan kalimat yang satu dengan yang lain secara tepat. Hal ini sesua dengan pendapat bahwa kohesi berfungsi menghubungkan kalimat yang satu dengan yang lain (Zhang, 2017) Pernyataan tersebut diperkuat oleh pendapat (Graham, 2018) bahwa kontribusi terpenting dalam membentuk keutuhan (koheren) adalah kepaduan (kohesi). Terkait dengan hal tersebut, penelitian ini akan mendeskripsikan ragam penggunaan penanda kohesi yang ada dalam rubrik pembaca menulis di Koran Jawa Pos.

\section{Hakikat Wacana}

Terkait dengan wacana, sejumlah pakar bahasa menjelaskan. Pendapat pertama menyatakan bahwa perwujudan kebahasaan (kata atau kalimat) yang lengkap dan utuh mengenai kejadian komunikaasi disebut discourse atau wacana. (Deyreh, 2012). Dalam praktiknya komunikasi bisa dimunculkan dalam bentuk lisan maupun tulis. Senada dengan pernyataan tersebut, Prohorets \& Plekhanova (2015) menyatakan wacana merupakan rentetan kalimat yang berkaitan dan membentuk makna yang serasi di antara kalimat itu. Pernyataan ini dapat dipertegas bahwa rentetan kalimat yang berkaitan yang menghubungkan proposisi yang satu dengan proposisi yang lain membentuk satu kesatuan dinyatakan dengan wacana.

Fokus dari pengertian ini adalah pentingnya unsur kesatuan hubungan antarkalimat dan keserasian makna di dalam wacana. Konsep ini sesuai dengan pernyataan bahwa satuan bahasa yang lengkap itu disebut dengan wacana (Costa et al., 2015). Pada tataran hierarki kebahasaannya, wacana merupakan satuan gramatikal tertinggi atau terbesar. Wacana dikatakan lengkap apabila di dalamnya memiliki pikiran, konsep, gagasan, dan ide yang utuh sehingga mampu dipahami secara jelas, utuh, dan tepat oleh pembaca atau pengengar.

Berdasarkan pendapat tersebut dapat disimpulkan, wujud wacana dapat dipastikan berupa kumpulan kalimat yang padu dan utuh (Abdi et al., 2010). Selanjutnya, kalimat merupakan kumpulan sejumlah kata dan kata berupa kumpulan suku kata serta kata terwujud dari kumpulan huruf. Secara teoretis, wacana tulis merupakan karangan yang lengkap dan utuh, sedangkan wacana lisan berwujud tuturan seseorang yang mampu diterima atau dipahami isinya 


\section{Efektor, Volume 8 Issue 1, 2021, Pages 59-68 \\ Andri Pitoyo}

oleh pendengar. Dengan demikian, satuan bahasa terlengkap yang dibentuk oleh rentetan kalimat secara kontinuitas, kohesif, dan koheren sesuai dengan konteks situasi bisa dinyatakan sebagai wacana.

\section{Jenis Wacana}

Jenis wacana bisa diklasifikasikan berdasarkan bentuk, media yang digunakan dalam menyampaikan ide, bahasa, dan cara maupun tujuan penyampaiannya, (He, 2014). Berdasarkan bentuknya, wacana dapat dikelompokkan menjadi tiga bentuk, yaitu wacana prosa, puisi, dan drama. Berdasarkan media yang digunakan wacana terdiri atas wacana tulis dan wacana lisan. Berdasarkan sifat atau jenis pemakaiannya wacana digolongkan menjadi wacana monolog dan dialog. Sedangkan ditinjau dari aspek bahasa yang digunakan, wacana dibagi (a) wacana bahasa nasional (Indonesia), (b) wacana bahasa lokal atau daerah ( Sunda, Madura, dan lainnya), (c) wacana bahasa internasional (Inggris), dan (d) wacana bahasa lainnya (Perancis, Arab, Belanda, dan yang lain.

Terkait teknik dan sasaran penyajiannya, secara spesifik wacana dikelompokkan 5 (lima) jenis ; deskripsi, eksposisi, narasi, argumentasi, dan persuasi (Souto-Manning, 2014). Wacana deskripsi merupakan wacana yang disajikan penutur dengan cara menggambarkan objek/peristiwa sejelas-jelasnya sehingga pembaca/pendengar seakan-akan berada atau mengalami peristiwa atau berada pada objek yang dimaksud. Sedangkan eksposisi merupakan wacana yang diungkapkan penutur dengan cara memberitahu (mengekspos) sejumlah informasi agar pembaca/pendengar "menjadi tahu" informasi tersebut. Sedangkan narasi merupakan wacana yang menekankan pada kronologis waktu, diujarkan oleh orang pertama atau ketiga. Wacana narasi menekankan substansi cerita secara urut dan sistematis. Sementara itu, wacana argumentasi berorientasi pada cara penutur mengungkapkan idenya dengan mmanfaat argument atau alasan. Penutur biasanya mengungapkan sesuatu ide secara spesifik (bersifat umum) kemudian diikuti dengan argumen. Dan, wacana persuasi berorientasi pada cara penutur dalam mengungkapkan idenya dengan cara menyakinkan atau memengaruhi pembaca/pendengar untuk melakukan seperti apa yang diinginkan penutur.

Klasifikasi wacana juga diungkapkan oleh (Musolff, 2012) yang menyatakan bahwa discourse bersifat naratif, ekspositorik, deskriptif, prosedural, dan hortatorik. Narative discourse merupakan rangkaian kisah yang menyajikan suatu hal atau kejadian dengan urut agar pembaca bisa memetik hikmah dari cerita itu. Exposition discourse adalah wacana yang berusaha menerangkan (menjelaskan) pokok pikiran yang dapat memperluas pengetahuan pembaca atau pendengar. Descriptive discourse merupakan rangkaian tuturan yang menggambarkan atau melukiskan suatu objek atau kejadian, baik berdasarkan pengalaman maupun pengetahuan penuturnya. Sedangkan procedure discourse merupakan rangkaian ungkapan atau tuturan yang melukiskan sesuatu secara berurutan dan sistematis unsur-unsurnya sehingga antara unsur yang satu denganlain berkait secara urut (dan tidak bisa dibolak-balik). Dan, hortatorik discourse merupakan tuturan menekankan pada usaha memengaruhi atau mengajak serta berusaha meneguhkan pendapat penutur. 


\section{Kohesi Leksikal (Penanda Hubung Leksikal)}

Dalam hal ini, kohesi leksikal diartikan sebagai tanda hubungan antar unsur dalam wacana secara semantik. (Graham, 2018) mengemukakan bahwa untuk menghasilkan twacana yang lengkap dan terpadu, penutur harus mengikuti diksi (kata) yang sesuai dengan isi wacana yang diinginkan. Hubungan kohesif yang dibuat berdasarkan aspek leksikal ini dilakukan dengan memilih kata-kata yang cocok, sehingga isi wacana tersebut dapat mengungkapkan hubungan yang bermakna atau hubungan semantik antara satu satuan bahasa dengan satuan bahasa lain dalam wacana (Ghazali, 2010).

Secara konseptual, unsur-unsur kohesi leksikal dalam suatu wacana dapat dibedakan menjadi sinonim (persamaan), antonim (lawan kata), hiponim (hubungan parsial atau isi), repetisi (pengulangan), kolokasi (kata-kata sanding) dan ekuivalensi (kesepadanan). Tujuan penggunaan unsur-unsur leksikal tersebut adalah untuk memperoleh efek intensitas makna bahasa, kejelasan informasi, serta pengaruh estetika atau unsur keindahan bahasa lainnya (Hua et al., 2007).

\section{Sinonim}

Sinonim dapat diartikan persamaan kata; atau ungkapan yang kira-kira memiliki makna yang sama dengan ungkapan lainnya. Menurut bentuk satuan bahasa (lingual), sinonim dikelompokkan lima jenis; 1) bentuk bebas dengan bentuk terikat), 2) kata dengan kata, 3) kata dengan frasa atau sebaliknya, 4) frasa dengan frasa, dan 5) klausa/ kalimat dengan klausa/ kalimat.

\section{Antonim}

Antonim dimaknai sebagai kata-kata yang berlawanan atau oposisi makna. Oposisi makna yang dimaksud bersifat hubungan, mutlak, hirarkial, kutub, dan majemuk.

\section{Hiponim}

Yakni kata, frasa, dan kalimat yang maknanya dipandang sebagai elemen makna satuan bahasa yang lain.

\section{Repetisi}

Maksudnya pengulangan satuan atau unit linguistik dan dianggap penting untuk menekankan hal yang penting. Menurut posisi unsur bahasa yang diulang dalam satu baris, klausa atau kalimat, pengulangan dikelompokkan : 1) Epizeuksis , 2) Tautotes , 3) Anafora, 4) Epistrofa, 5) Pengulangan Simploke, 6) Pengulangan Mesodiplosis, 7) Pengulangan Epanalepsis, 8) Pengualangan Anadiplosis , dan 9) Pengulangan Utuh.

\section{Kolokasi}

Merupakan kecenderungan sejumlah kata untuk bergabung secara teratur dan logis (lazim) dalam praktik berbahasa. Faktanya setiap bahasa mempunyai kemampuan menggabungkan suatu kata / istilah terhadap kata atau istilah lainnya. Lazimnya, pada saat proses penggabungan ada sejumlah kosa kata yang keselitan menyatu karena menimbulkan hubungan yang tidak logis.

\section{Ekuivalensi}

Merupakan unsur kesepadanan dalam praktik pembentukan sejumlah kata. Kesepadanan menekankan pada pembentukan morfem bebas dan terikat dalam konteks yang sepadan. 


\section{METODE PENELITIAN}

Penelitian ini menggunakan pendekatan deskriptif (metodologis) dan analisis wacana kritis (teoretis), dengan metode dokumentasi dan analisis isi teks berupa Koran Jawa Pos. Metode dokumentasi dipakai untuk menemukan data tentang hal atau variabel yang berupa catatan, Koran, agenda-agenda lain (Arikunto, 2013:265), karena datanya berupa kata (kohesi) yang ada dalam Koran Jawa Pos Tahun 2020. Data penelitian ini bersumber dari Koran Jawa Pos bulan Mei dan Juni 2020 yang memfokuskan pada rubrik Pembaca Menulis. Sedangkan datanya dikumpulkan melalui teknik simak dan catat (Fitriana, 2019). Data yang sudah terkumpul dianalisis dengan deskriptif kualitatif yang memanfaatkan referensi keilmuwan linguistik (Emzir, 2012).

\section{HASIL DAN PEMBAHASAN}

\section{Kohesi Leksikal berupa Repetisi}

Sesuai dengan sudut pandang tempat satuan lingual yang diulang dalam baris, klausa atau kalimat, terdapat delapan repitisi.repetisi. Tetapi dalam penelitian ini ditemukan enam macam, yaitu repetisi epizeuksis, repetisi tautotes, repetisi anafora, repetisi epistrofa, repetisi mesodiplosis, dan repetisi anadiplosis.

\section{Repetisi Epizeuksis}

Saya berlangganan Smartfren sudah hampir tiga tahun. Akhir-akhir ini saya merasakan penurunan kecepatan koneksi pada modem Smartfren yang saya pakai. Saya tinggal di daerah Surabaya Utara, dekat dengan Surabaya Pusat.

(KLJP R1/JP7M)

Menanggapi surat yang disampaikan Ibu Intan Kurnia W. dalam Pembaca Menulis Jawa Pos (27/4) yang berjudul sulitnya Menutup Kartu Kredit, kami sampaikan...Dalam kesempatan ini pula kami menyampaikan permohonan maaf atas ketidaknyamanan yang dialami.

(KLJP R2/JP7M)

Pada potongan wacana (1) tersebut terjadi beberapa repetisi atau pengulangan epizeuksis, yaitu kata saya pada kalimat 1) mengalami pengulangan saya pada kalimat 2) dan 3). Kemudian pada potongan wacana (2) terdapat kata kami pada kalimat 1) dan diulang kembali pada kalimat 2).

\section{Repetisi Tautotes}

Permohonan paspor kedua anak Bapak secara otomatis ditolak sistem karena adanya kesalahan input saat mengajukan permohonan secara online sehingga harus mengajukan permohonan ulang (dengan nomor permohonan baru)

(KLJP R3/JP7M)

Pada data (3) tersebut terdapat repetisi atau pengulangan jenis tautotes. Repetisi yang pertama berupa kata permohonan dalam satu kalimat diulang sebanyak empat kali. Hal ini menunjukkan bahwa satuan lingual yang membangun wacana tersebut saling berkaitan dan mengandung peekanan maksud.

\section{Repetisi Anafora}

Saya mendapat pelayanan yang baik. Ketika itu, saya menanyakan penyambungan baru dengan nomor registrasi 5114612030054 tanggal 18 Maret 2019. Saya mendapat penjelasan, karena harus memasang jaringan baru. 
(KLJP R4/JP15M)

Pada data (4) tersebut terdapat repetisi anafora dalam konstruksi awal kalimat 1) yaitu frasa saya mendapat, diulang penulisannya di awal kalimat 3). Hal ini menunjukkan penulis ingin meyakinkan pembaca agar pesan yang disampaikan dapat memperjelas apa yang dimaksudkan pada kalimat 1) yaitu mendapatkan sesuatu.

\section{Repetisi Epistrofa}

Meski demikian, pekerjaan yang mengancam nyawa itu tidak menyurutkan nyali masyarakat kita untuk menjadi penggali sumur. Bahkan, di beberapa tempat seperti tiang listrik dan ruang-ruang kosong sekitar kita, banyak tempelan info iklan penggali sumur.

(KLJP R5/JP19M)

Pada data (5) tersebut terdapat jenis repetisi epistrofa yaitu dalam kalimat 1) berupa frasa penggali sumur yang terletak di akhir kalimat yang diulang pada kalimat 2. Hal ini menunjukkan bahwa penulis ingin menekankan pembicaraan terhadap profesi tersebut agar pembaca lebih jelas maksud dari penulis.

\section{Repetisi Mesodiplosis}

Suatu hari di lampu merah pengendara motor di belakang motor saya menowel punggung saya. Ketika menoleh, saya lihat seorang perempuan memberi tahu saya untuk mengingatkan pengendara motor di depan saya bahwa tas punggungnya terbuka. Begitu saya ingatkan, pemuda pengendara motor di depan saya itu segera menutup tas punggungnya.

(KLJP R6/JP 20M)

Pada data (6) tersebut terdapat frasa 'pengendara motor' pada kalimat 1). Frasa tersebut mengalami pengulangan pada kalimat 2) dan 3). Dengan demikian pesan yang disampaikan penulis kepada pembaca diharapkan dapat dipahami dan dimengerti dengan baik.

\section{Repetisi Anadiplosis}

Perlu diingatkan bahwa timnas yang selama ini kita dukung adalah timnas Indonesia, bukan mewakili PSSI. PSSI sesungguhnya hanyalah penyalur dan pelayan hasrat rakyat Indonesia atas sepak bola.

(KLJP R7/JP24M)

Pada data (7) tersebut terdapat repetisi anadiplosis. Yaitu kata PSSI yang terletak di akhir kalimat 1), diulang penulisannya di bagian awal kalimat 2). Hal ini menunjukkan sikap penulisan yang dilakukan penulis dengan mengulang kata atau frasa yang sama di akhir kalimat dengan menggunakannya langsung di awal kalimat sebagai upaya untuk meyakinkan pembaca agar memahami maksud penulis dengan baik. Dengan menggunakan kata atau frasa yang sama secara berulang-ulang penulis berusaha menyampaikan maksud penting atau hal utama dalam wacana tersebut sehingga pembaca memiliki pemikiran sama dengannya.

\section{Kohesi Leksikal berupa Sinonim \\ Sinonimi kata dengan kata}

Mengundurkan diri hanya pantas untuk seseorang yang beralih atau pindah profesi yang lebih baik dan lebih mulia. 
(KLJP S1/JP9J))

Pada data (8) tersebut terdapat kata beralih pada kalimat 1) yang memiliki makna sama dengan kata pindah yang juga terdapat dalam kalimat 1. Hal tersebut menunjukkan bahwa penggunaan sinonimi kata diperlukan untuk memperjelas maksud. Penulis khawatir kata beralih yang dipakai dalam kalimat 1) masih belum dipahami pembaca, sehingga dimunculkan kata bersinonim pindah pada kalimat 2)

\section{Sinonim kata dengan frasa atau sebaliknya}

Baliho atau papan reklame memang menjadi salah satu pemasukan daerah dan media informasi bagi masyarakat

(KLJP S2/JP2J)

\section{Sinonimi frasa dengan frasa}

Saya berharap Bu Khofifah segera memberikan reward atas prestasi mereka. Orang nomor satu di Jawa Timur tentu tidak ingin atletnya pindah ke daerah lain.

(KLJP S3/JP4J)

Pada data (10) tersebut terdapat kesinoniman pada frasa Bu Khofifah pada kalimat 1) dengan frasa orang nomor satu di Jawa Timur pada kalimat 2). Penggunaan frasa yang memiliki makna yang sama ini ditujukan agar wacana lebih menarik minat baca pembaca dan terkesan tidak monoton. Sehingga pemilihan frasa seperti inilah yang mampu membuat pembaca memahami wacana dengan baik.

\section{Sinonimi klausa/kalimat dengan klausa/kalimat}

Ternyata, aplikasi itu tidak bisa berjalan karena tidak berfungsinya peranti GPS yang ada. Ketika saya pakai sebagai GPS navigator, simbol segitiga sebagai penunjuk jalan tidak bergerak dari posisi awal (my location) sampai ke tempat tujuan (destination). adang mengakibatkan gigi terlepas dari tempatnya. Gigi yang tanggal sebelum waktunya, selain memengaruhi estetik, tentu akan mengganggu proses pengunyahan makanan dan bisa mengakibatkan gigi sebelahnya berpindah posisi (bergeser)

$$
\text { (KLJP S4/JP10J) }
$$

Pada data (11) tersebut dalam kalimat 1) terdapat klausa tidak berfungsinya peranti GPS yang ada. Jika dicermati klausa ini bersinonim dengan klausa simbol segitiga sebagai penunjuk jalan tidak bergerak dari posisi awal (my location) sampai ke tempat tujuan (destination). Makna peranti GPS yang ada, oleh penulis dimaksudkan sebagai simbol segitiga sebagai penunjuk jalan. Selain itu, Hal ini menunjukkan bahwa penulis berusaha memberikan penjelasan sedetail mungkin agar maksud pada kalimat 1) bisa dipahami pembaca dengan baik.

Kohesi Leksikal berupa Antonim.

\section{Oposisi Mutlak}

Kami tidak menemukan nilai minimal dan nilai maksimal pada realisasi penerimaan SMAN 5 Surabaya.

(KLJP A1/JP10J) 
Pada data (12) tersebut terdapat oposisi atau antonimi mutlak pada kata minimal dengan kata maksimal pada kalimat 1). Penggunaan oposisi mutlak dalam wacana dimaksudkan agar pembaca dapat membedakan dua jenis makna kata yang diterapkan dan digunakan dalam kehidupan sangatlah berbeda.

\section{Oposisi Kutub}

Awalnya dipuja-puja, ujung-ujungnya kerap dihina-hina.

(KLJP A2/JP18J)

\section{Oposisi Hubungan}

Berulang-ulang saya tanyakan, jawabannya selalu sama, yakni spare part belum datang.

(KLJP A3/JP13J)

Pada data (14) dalam kalimat 1) tersebut terdapat kata tanyakan dan jawabannya. Munculnya kata jawabannya karena dipengaruhi oleh adanya kata tanyakan. Hal tersebut menyebabkan adanya oposisi hubungan karena kedua kata tersebut bersifat saling melengkapi satu sama lain. Sehingga hadirnya salah satu kata memungkinkan adanya kata lain yang beroposisi dalam wacana.

\section{Oposisi Hirarkial}

Kemudian saya berpikir, bagaimana para koruptor yang memakan uang yang bukan haknya yang nilainya miliaran sampai triliunan itu, ya?

\section{Oposisi Majemuk}

(KLJP A4/JP15J)

Jumat anak saya diantar ibu dan adik saya untuk imunisasi dan mendapat nomor antrean 133. Vaksin dijanjikan tersedia, ternyata malah tidak ada.

(KLJP A5/JP16J)

Data (16) kalimat 1) terdapat oposisi majemuk beberapa kata atau gabungan kata, yaitu anak saya, ibu saya, dan anak saya. demikian juga pada kalimat 2) terdapat oposisi antara kata tersedia dengan tidak ada. Hal ini menunjukkan beberapa kata yang beroposisi tersebut sengaja dilakukan berurutan untuk menaikkan daya pikir pembaca agar dapat memahami maksud penulis dengan lebih terperinci dan bertahap.

\section{SIMPULAN}

Penelitian ini menemukan data penggunaan repetisi, sinonim, dan antonim di setiap kalimat yang mengandung opini publik. Secara keseluruhan disimpulkan bahwa penggunaan penanda kohesi tersebut dimaksudkan untuk memperjelas maksud, menegaskan makna, dan merinci suatu keadaan, dan menghindari ketidakjelasan keinginan. Dengan demikian, dapat dinyatakan bahwa kalimat yang mengandung keinginan (dalam rubrik pembaca menulis) banyak menggunakan tiga kohesi tersebut dengan harapan agar apa yang ditulis (penulis) bisa dipahami dan ditindaklanjuti (pembaca).

Keterangan:

KLJP = Kohesi Leksikal Jawa Pos

$\mathrm{R} \quad=$ Repetisi 
$S \quad=$ Sinonim

A $\quad=$ Antonim

\section{DAFTAR RUJUKAN}

Abdi, R., Rizi, M. T., \& Tavakoli, M. (2010). The cooperative principle in discourse communities and genres: A framework for the use of metadiscourse. Journal of Pragmatics, 42(6), 1669-1679. https://doi.org/10.1016/j.pragma.2009.11.001

Arikunto, S. (2013). Prosedur Penelitian: Suatu Pendekatan Praktik (XV). PT. Rineka Cipta.

Costa, C., Cardoso, A. P., Lima, M. P., Ferreira, M., \& Abrantes, J. L. (2015). Pedagogical Interaction and Learning Performance as Determinants of Academic Achievement. Procedia - Social and Behavioral Sciences, 171, 874-881. https://doi.org/10.1016/j.sbspro.2015.01.203

Danglli, L., \& Abazaj, G. (2014). Lexical cohesion, word choice and synonymy in academic writing. Mediterranean Journal of Social Sciences, 5(14), 628-632. https://doi.org/10.5901/mjss.2014.v5n14p628

Deyreh, E. (2012). Implication of Interactional Learning Practice in Classroom. Procedia - Social and Behavioral Sciences, 46, 2869-2871. https://doi.org/10.1016/j.sbspro.2012.05.579

Emzir. (2012). Metodologi Penelitian Kualitatif: Analisis Data (3rd ed.). PT. Raja Grafindo Persada. http://www.rajagrafindo.co.id

Evi, F., \& Bakti, H. (2016). Analisis Wacana Kritis Pemberitaan Harian Suara Merdeka, Harian Republika, Harian Kompas, dan Tabloid Derap Guru dalam Pembentukan Citra Guru. Seloka: Jurnal Pendidikan Bahasa Dan Sastra Indonesia, 5(2), 136-147. http://journal.unnes.ac.id/sju/index.php/seloka

Fitriana, R. A. (2019). Analisis Wacana Kritis Berita Online Kasus Penipuan Travel Umrah (Model Teun a. Van Dijk). BASINDO: Jurnal Kajian Bahasa, Sastra Indonesia, Dan Pembelajarannya, 3(1), 44-54. https://doi.org/10.17977/um007v3i12019p044

Ghazali, A. S. (2010). Pembelajaran Keterampilan Berbahasa:dengan Pendekatan KomunikatifInteraktif (A. N. Falah (ed.); I). PT Rafika Aditama. www.refika-aditma.com

Graham, P. (2018). Ethics in critical discourse analysis. Critical Discourse Studies, 15(2), 186203. https://doi.org/10.1080/17405904.2017.1421243

He, Q. (2014). A Study of Lexical Cohesion Theory in Reading Comprehension. International Journal of English Linguistics, 4(6), 143-150. https://doi.org/10.5539/ijel.v4n6p143

Hua, Z., Seedhouse, P., Wei, L., \& Cook, V. (2007). Language learning and teaching as social inter-action. In Z. Hua, P. Seedhouse, L. Wei, \& V. Cook (Eds.), Language Learning and Teaching as Social Inter-action (10th ed.). Palgrave Macmillan. https://doi.org/10.1057/9780230591240

Musolff, A. (2012). The study of metaphor as part of critical discourse analysis. Critical Discourse Studies, 9(3), 301-310. https://doi.org/10.1080/17405904.2012.688300

Prohorets, E., \& Plekhanova, M. (2015). Interaction Intensity Levels in Blended Learning Environment. Procedia - Social and Behavioral Sciences, 174(3822), 3818-3823. https://doi.org/10.1016/j.sbspro.2015.01.1119

Souto-Manning, M. (2014). Critical narrative analysis: The interplay of critical discourse and 
Efektor, Volume 8 Issue 1, 2021, Pages 59-68

Andri Pitoyo

narrative analyses. International Journal of Qualitative Studies in Education, 27(2), 159-180. https://doi.org/10.1080/09518398.2012.737046

Zhang, X. (2017). Reading-writing integrated tasks, comprehensive corrective feedback, and EFL writing development. Language Teaching Research, 21(2), 217-240. https://doi.org/10.1177/1362168815623291 